\title{
Nasal-lateral assimilations: typology and structure
}

\author{
Deepthi Gopal \\ University of Manchester
}

\section{Introduction}

Assimilatory nasalization and lateralization across heterosyllabic nasal-lateral (NL) and lateral-nasal (LN) clusters are well-attested across various languages. Representative examples are shown in (1) and (2):

(1) Nasalization: NL/ML or LN/LM realised as a NN sequence.

(a) Korean (Iverson \& Sohn 1994)

$\begin{array}{lll}\text { /sam-lju/ } & \text { [sam.nju] } & \text { 'third-rate' } \\ \text { /jən-lak/ } & \text { [jə⿹.nak] } & \text { 'downfall' } \\ \text { Gagauz (Turkic; } & \text { Özkan 1996) } & \\ \text { /ajdin-lik/ } & \text { [ajdin.nik] } & \text { 'bright' } \\ \text { /al.nin.da/ } & \text { [an.ninda] } & \text { 'ours' }\end{array}$

(2) Lateralization: NL/ML or LN/LM realised as a LL sequence.

(a) Alutor (Chukotko-Kamchatkan; Kibrik, Kodzaso, Muravyova 2004)

$$
\text { /t-n-levə-n/ [təl.lev.ən] 'I took it with me' }
$$

(b) Fur (Nilo-Saharan; Jakobi 1990)

$\begin{array}{lll}\text { /bàin-le/ } & \text { [bàil.le] } & \text { 'to/from the elder brother' } \\ \text { /deen leel/ } & \text { [deel.lèèl] } & \text { 'his donkey' }\end{array}$

In this paper, I address the following questions: do all patterns analogous to (1) and (2) admit a unified analysis? Are there any systematic constraints governing assimilation in sequences of nasals and laterals, and if so, what is the nature of such constraints? Previous work provides heterogeneous analyses of similar patterns in individual languages. Assimilations in NL sequences in Korean and Sakha (Davis \& Shin 1999, Baertsch 2002) have been attributed to the driving force of Syllable Contact - that is, to constraints penalizing rising sonority across the syllable boundary. NL/LN lateralization in Toba Batak, Selayarese, and Klamath has been analyzed as deriving from constraints promoting feature sharing (SHARE-F; Yip 2004, 2005), and as spreading either of laterality or of sonorancy in the literature on feature geometries (Blevins 1994, Iverson \& Sohn 1994).

I aim to show in this work that assimilations in sequences of nasals and laterals are driven neither by sonority nor by feature sharing, but by a markedness constraint penalizing non-identical but phonologically similar adjacent segments - which I formalize here in an asymmetric implementation of Agreement by Correspondence (ABC; Walker 2000, 2001; Hansson 2001; Rose \& Walker 2004). I derive arguments for this approach from the typology of assimilations in NL and LN sequences, which I present in section 2: evidence from a cross-linguistic survey ${ }^{1}$ demonstrates that there are consistent implicational generalizations governing the distribution of assimilation targets. In sections 3 and 4, I show that an approach driven by dispreference for non-identical but similar segments correctly predicts a relative absence of assimilation in heterorganic sequences (LM, ML) and in stop-lateral sequences. In section 5, I show that implementations of

\footnotetext{
* I'm grateful to Yuni Kim, Ricardo Bermúdez-Otero, and Wendell Kimper for supervisory support and detailed feedback, and to audiences at AMP 2015 and OCP 13 for helpful comments and suggestions.

1 For the complete list of languages surveyed and patterns observed, please see the appendix available at http://personalpages.manchester.ac.uk/staff/deepthi.gopal/papers/amp15appendix.pdf

(C) 2016 Deepthi Gopal

Proceedings of AMP 2015

Completed March 31, 2016
} 
$\mathrm{ABC}$ in which correspondence is non-symmetric do not predict assimilation direction, but can predict cases in which the interaction between segments depends on their linear order within the string: allowing asymmetric correspondence in our analysis correctly predicts the generalization that NL sequences preferentially undergo assimilation relative to $\mathrm{LN}$ sequences. In contrast to the above, analyses invoking constraints on sonority or on shared features cannot account for this entire set of generalizations simultaneously.

\section{The typology of nasal-lateral effects}

Here, I present and analyze typological observations drawn from a cross-linguistic survey of assimilations in adjacent nasals and laterals. The sample of 46 languages represents the totality of identifiable languages satisfying the criterion for inclusion, which was the attested presence of any assimilatory phenomena in sequences containing both nasals and laterals; I do not consider non-assimilatory repairs in this work. A supplementary search was conducted to identify languages for which assimilations arise in stop-lateral (TL) sequences; it emerges that this is a subset of the previous sample, as I will discuss below. Further information on each of the 46 languages exhibiting these assimilations is available in the appendix.

2.1 Asymmetries in targeting Within a given language, what combinations of assimilations are possible? In describing the sequences targeted by assimilation, I consider two parameters, giving four distinct sequence types to address: whether the sequence is homorganic (NL, LN) or heterorganic (ML, LM), and whether the nasal precedes (NL, ML) or follows the lateral (LN, LM) in the string. (Each type of sequence can then either be lateralized (to LL), nasalized (to $\mathrm{NN}, \mathrm{MN}$, or MM), or remain unrepaired.) We are then interested in the size of the set of possible systems: are there logical combinations of sequence type and repair type that remain unattested? In fact, we see a fairly restricted set of existent systems: 4 of a theoretically possible 15 (the maximum number of unique systems generated by four possible target sequences). As an exploration of this set, I present below in (3) a partial overview of the survey results, dealing exclusively with the target of repair; combinations of assimilations not listed are not attested in the data.

\begin{tabular}{|c|c|c|c|c|c|}
\hline \multicolumn{6}{|c|}{ Attested systems } \\
\hline NL & LN & ML & LM & Number of languages & Examples \\
\hline$\checkmark$ & $\bar{v} \checkmark$ & $\checkmark$ & & 5 & $\begin{array}{l}\text { Korean (Iverson \& Sohn 1994) } \\
\text { Koasati (Kimball 1991) }\end{array}$ \\
\hline$\checkmark$ & $\checkmark$ & & & 12 & $\begin{array}{l}\text { Leti (Blevins 1994) } \\
\text { Baghdadi Arabic (Youssef 2013) }\end{array}$ \\
\hline$\checkmark$ & & $\checkmark$ & & 13 & $\begin{array}{l}\text { Fur (Jakobi 1990) } \\
\text { Meiteilon (Chelliah 1997) }\end{array}$ \\
\hline$\checkmark$ & & & & 11 & $\begin{array}{l}\text { Klamath (Blevins 1994) } \\
\text { Majorcan Catalan (Pons 2011) }\end{array}$ \\
\hline
\end{tabular}

(3) suggests that there are predictable asymmetries in the typology of nasal-lateral and lateral-nasal assimilations, and that there are significant gaps in the set of attested systems cross-linguistically. This can be explored further via several generalizations. First, LM sequences resist assimilation: across all languages surveyed, I find no evidence for either nasalization or lateralization in heterorganic sequences where the nasal follows the lateral, even in languages in which NL, LN, and ML are all assimilated (an example of which is given in 4).

(4) Koasati (Muskogean; Kimball 1991)

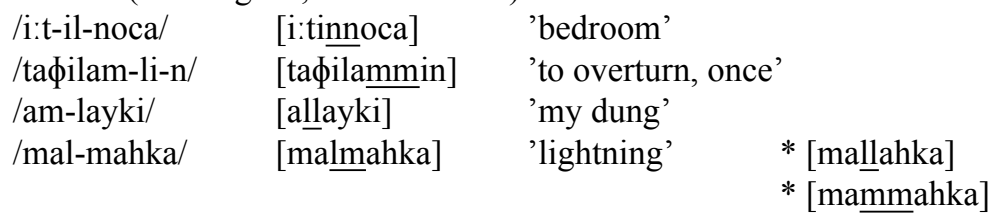

Second, assimilation in LN implies assimilation in NL, whether nasalizing or lateralizing. Assimilation across a homorganic lateral-nasal sequence /1.n/ occurs in 17 languages in the sample; /n.l/ assimilates in all such cases. I find 5 additional cases (Finnish, Sidamo, Choctaw, Somali, Kunuz Nubian) in which we do seem 
to see $\mathrm{LN}$ assimilation without NL; in all such cases, the repair is morphologically restricted and there is no evidence for the existence of underlying NL sequences at a similar level of affixation, so these are likely to represent incidental, language-specific gaps in inventory rather than robust counterexamples.

Third, assimilation in ML implies assimilation in NL. $/ \mathrm{m} .1 / \mathrm{l} / \mathrm{n} .1 /$ and $/ \mathrm{y} .1 /$ assimilations (both nasalizing and lateralizing) arise in 18 languages; all these languages also repair $/ \mathrm{n} .1 /$. In fact, all languages in our sample repair $N L$, save only those for which /nl/ appears unattested in underlying form (of course, it may always be possible that such a gap represents the result of NL repair at an earlier stage in the history of the language). ML and LN are independent of each other: a language may repair both of these types, may repair only ML or only LN, or may repair neither.

Fourth, assimilation in stop-lateral (TL) sequences implies assimilation in NL sequences. In 16 languages of this sample, TL sequences undergo (lateralizing) assimilation; I am unaware of any cases (external to this sample) in which stop-lateral sequences undergo assimilation, but nasal-lateral sequences remain unrepaired. This is not true for nasalizing assimilation in stop-nasal sequences (NT or TN), which occurs freely and independently of the state of NL; I will revisit the asymmetry between these types in arguing for a similaritybased analysis. We can then summarize the asymmetries outlined above with an implicational generalization regarding the susceptibility of various sequences to assimilation:

(5) Susceptibility to assimilation

homorganic $\mathrm{NL} \gg$ homorganic $\mathrm{LN} \approx$ heterorganic $\mathrm{ML} \gg$ heterorganic $\mathrm{LM}$

This is consistent with an analysis predicated on similarity: the most dispreferred target is heterorganic and therefore less similar than the homorganic sequence that is the best target. I will argue in [§5], after establishing our formalism, that the targeting of NL over LN and ML over LM represents an inherent asymmetry in the direction of correspondence (that is, NL sequences may enter correspondence and be subject to assimilation while LN sequences do not).

2.2 Asymmetries in selection of repair In [2.1], I have presented evidence for typological asymmetries in the targets of nasalizing and lateralizing assimilations: NL, LN, and ML sequences are not equally susceptible to assimilation. In this subsection, I briefly present cross-linguistic data on the direction and manner of assimilation. Implemented repairs may be either nasalizing or lateralizing, as (6). With regard to directionality, a given language may display consistently progressive assimilation, as in Xakas (Anderson 1998) and Tuvan (Harrison 2000), or consistently regressive assimilation, as in Moroccan Arabic (Harrell 1962), Tsakhur (Schulze 1997), and Pendau (Quick 2003). However, the most frequent cases in the sample are those in which no particular direction of assimilation is preferred. Instead nasalizing or lateralizing output may be selected either throughout, or for a particular place of articulation. This is outlined in (7).

(6) Nasalization or lateralization across sequence types

\begin{tabular}{c|c|c|c|c}
\hline Repair & NL & LN & ML & LM \\
\hline \hline Nasalization & 13 & 8 & 16 & 0 \\
Lateralization & 29 & 14 & 2 & 0 \\
\hline
\end{tabular}

(7) Direction of assimilation for various types of assimilating systems

\begin{tabular}{c|c|c|c|r}
\hline NL, LN, ML & NL, LN & NL, ML & Assimilation type & Examples \\
\hline \hline 0 & 0 & $7 ?$ & Consistently progressive & Xakas, Tuvan \\
\hline 0 & 2 & $1 ?$ & Consistently regressive & Moroccan Arabic, Tsakhur \\
\hline 2 & $2 ?$ & $7 ?$ & Nasalize all & Gagauz, Koasati \\
\hline 0 & $7 ?$ & $1 ?$ & Lateralize all & $?$ \\
\hline 0 & $2 ?$ & 0 & $\begin{array}{c}\text { Nasalize homorganic } \\
\text { Lateralize heterorganic }\end{array}$ & $\begin{array}{c}\text { Lateralize homorganic } \\
\text { Nasalize heterorganic }\end{array}$ \\
\hline 3 & $7 ?$ & 3 & Korean, Uighur (Hahn 1991) \\
\hline
\end{tabular}

I note that the categories into which I have divided assimilations in (7) seem to be the minimal set that accurately describes the observed behaviors, but that there is some overlap (marked with ?): we cannot distinguish between the nasalization of only homorganic clusters and the nasalization of all clusters in a system 
in which only homorganic sequences (NL, LN) are targeted, and we cannot distinguish between a constraint forcing strictly rightward assimilation and a constraint forcing nasalization irrespective of direction when only nasal-initial (NL, ML) sequences are targeted.

Taken together, (6) and (7) suggest that the resultant direction of assimilation may be less salient than the place specifications in the sequence. Lateralization is somewhat preferred in homorganic sequences, and nasalization is strongly preferred in heterorganic sequences. Although disambiguation is difficult here, few languages in the sample display clearly leftward or clearly rightward repair.

\section{Existing analyses}

Having established the structure of the typology in [\$2], we now have fairly simple desiderata for a successful analysis: we must be able to generate the four distinct systems observed in [2.1], and we must avoid overgeneration of the unattested types. In this section, I discuss the analyses that have been previously proposed for various cases in the sample, and show that these analyses all fail to account for significant portions of the typology; in following sections, I show that the asymmetric similarity-based account presents fewer descriptive issues.

3.1 Syllable contact NL assimilations in Korean and Sakha have been attributed to Syllable Contact (SyllCon) by Davis and Shin (1999), Davis and Baertsch (2000), and Baertsch (2002). The driving principle behind an analysis of this type is the cross-linguistic tendency to prefer falling sonority across a syllable boundary; flat or rising sonority (as in a sequence NL, where $\mathrm{N}$ is lower-sonority than L) is highly dispreferred, and must be repaired.

What typological predictions arise if we attribute assimilations across nasals and laterals to Syllable Contact? If SyLLCon (or related constraints on sonority profile) is sufficiently highly-ranked in a language to affect the sequence NL, then it is expected that all sequences with identical or worse sonority profile (that is, equivalent or sharper falling sonority) must also be repaired. This analysis therefore predicts that TL must be more susceptible to repair than $N L$, which is not concordant with our data. Although sonority considerations do correctly predict that NL is a better target for repair than LN, an analysis predicated on SyLLCoN alone overpredicts a lack of assimilation in NL: since the sonority contour in LN is weakly falling and thus favorable, constraints solely referring to sonority contour will underestimate the typological frequency of LN assimilations. Since the sonority hierarchy is generally assumed to be place-independent, Syllable Contact in itself doesn't predict an asymmetry between heterorganic and homorganic NL/ML sequences, which have otherwise identical sonority contours: if one type undergoes repair, then we predict that both NL and ML must be repaired.

In fact, for both Korean and Sakha, I argue that the Syllable Contact analysis provides an incomplete account of the observed data. Consider the Korean examples presented in (8) and (9) below; several oddities present themselves. [n.l] cannot surface and nor can obstruent-sonorant sequences, which is consistent both with the Syllable Contact model and with our typological observations. However, while [1.n] is also banned (un-attributable to the action of SYLLCON), [p.s] may surface, despite being a rising-sonority sequence (dispreferred) with a similar sonority contour to [n.l] (the constituent segments are equivalently distant from each other on the sonority hierarchy, though ranked differently).

(8) Korean assimilations (Iverson \& Sohn 1994)

$\begin{array}{lll}/ \text { han-kuk+mal/ } & \text { [hay.guy.mal] } & \text { 'Korean lg.' } \\ / \text { pat }{ }^{\text {h+noysa/ }} & \text { [pan.noy.sa] } & \text { 'dry field farming' } \\ \text { /sam-lju/ } & \text { [sam.nju] } & \text { 'third-rate' } \\ \text { /jəy-lak/ } & \text { [jəy.nak] } & \text { 'downfall' } \\ \text { /səl-nal/ } & \text { [səl.lal] } & \text { 'New Year' }\end{array}$

(9) Stop-fricative non-assimilation in Korean

/kuk+su/ [kuk.su] 'noodle'

/sam+kjəp+sal/ [sam.gjəp.sal] 'pork belly'

I present data from Sakha in (10) and (11). In Sakha, we find widespread desonorization or obstruentization, as in (10), applying across clusters with rising, flat, and falling sonority; this is entirely 
consistent with a SYLLCon or sonority-motivated analysis with the additional stipulation that simply any degree of falling sonority is apparently insufficient, and sonority drop must be maximized where possible, forcing obstruentization (this is not without precedent: cf. Gouskova 2004 on sonority-drop-maximizing obstruentization in Kyrgyz). The data in (11) complicates this picture: despite other repairs in clusters with falling sonority, /1.1/ may surface unrepaired despite unfavorable flat sonority, /1.t/ is lateralized (creating a significantly less favorable sonority contour) in violation of SYLLCoN, and /n.1/ is repaired to flat sonority rather than to maximally falling sonority.

(10) Sakha (Turkic, Siberia) affix onsets (Krueger 1962; Odden 2013)

/ubaj-lar/ [ubaj.dar] 'elder brothers'

/køtør-lar/ [køtør.dør] 'birds'

lat-lar/ [at.tar] 'horses'

(11) /kuul-lar/ [kuul.lar] 'sacks'

/uol-tayar/ [uol.layar] 'son-comparative'

/oron-lar/ [oron.nor] 'beds'

An examination of the data for both Korean and Sakha suggests that their behavior is problematic for any claim that Syllable Contact is responsible for all phenomena at the boundary in either language. Although certain portions of the existing assimilatory phenomena in these cases (e. g. the dispreference for obstruentsonorant sequences) are consistent with the predictions made by SYLLCon, the ban on LN and the tolerance for rising sonority outside a sonorant context requires an alternate analysis. In other languages in our sample (e. g. Koasati in (4)), we see NL and LN treated symmetrically and a lack of evidence elsewhere in the phonology for sonority-based constraints. I (will) argue that systems like these are not problematic for an account grounded in phonological similarity.

3.2 Feature spreading and sharing Various cases of nasalization and lateralization across relevant clusters have been attributed to constraints promoting feature sharing, or (relatedly) in the feature-geometric literature to feature spread: Yip 2005 on Toba Batak, Moroccan Arabic, Ponapean; Blevins 1994 on Leti, Klamath, Ponapean and others. I (briefly) discuss some insufficiencies in these accounts: although [lateral]sharing appears to account for the cases directly attributed to such constraints (unlike the complications observed for SYLLCON), proposing constraints of this nature will generate typologies that are both insufficient and over-predictive.

3.2.1 Place sharing It's possible to predict assimilations in heterorganic sequences (ML, LM) by modeling them as the interaction of SHARE[F] for place features and a ban on non-coronal laterals (which has some cross-linguistic support): but we cannot predict assimilation in homorganic sequences. Refer also to (8): we see, quite frequently, assimilatory nasalization in which place is not shared.

3.2.2 Lateral sharing Attributing nasalization and lateralization to lateral sharing cannot distinguish between NL and LN repair (in fact, Syllable Contact provides a superior analysis in this instance) and therefore is inadequately restrictive relative to the significant asymmetry in the observed typology. If we stipulate directionality to eliminate this problem, we cannot predict systems of the Korean type above: in which NL, ML, and LN are all assimilated, but LM remains unrepaired.

\section{Agreement by Correspondence}

In this section, I provide [4.1] a brief overview of the Agreement by Correspondence framework and its properties and utility, and [4.2] model the typological problems discussed in [§2]. Agreement by Correspondence, henceforth ABC (Walker 2000, 2001; Hansson 2001; Rose \& Walker 2004, Bennett 2013), is a theory of assimilation that was originally formulated to handle long-distance consonant agreement, and later vowel harmony (Walker 2009, Rhodes 2012) and long-distance dissimilation. Recent and ongoing work (Inkelas \& Shih 2013, Lionnet 2014) further extends ABC to account for strictly local effects; no inherent property of the formalism prevents this.

The essential insight suggested by $\mathrm{ABC}$ is that harmony and disharmony are driven by similarity, which is encoded in the analysis: assimilation, rather than spreading, derives from the interaction between those 
surface segments which pass a certain threshold on phonological similarity, as determined by shared features. Participating segments in an assimilatory process must share some sort of featural specification - for example, voice, sonorancy, or nasality. Such segments are in correspondence; corresponding segments are then required to agree for another feature. After Inkelas and Shih (2013), we may say that this correspondence is 'unstable': for two segments to interact, they must be sufficiently similar (i. e. in correspondence), but non-identical corresponding segments are then too uncomfortably similar to coexist within a certain distance, and must be repaired either by assimilation or dissimilation. For the typological and operational problems I pose in this paper, I suggest that the machinery of $\mathrm{ABC}$ is well-equipped to provide a solution; in the following section [\$5] I argue that in order to fully capture the asymmetry between sequences in which the ordering of $\mathrm{N}$ and $\mathrm{L}$ differ, we require the implementation of correspondence relations in $\mathrm{ABC}$ to be asymmetric.

4.1 Formalism More formally, an analysis of assimilation in $\mathrm{ABC}$ requires two components: segments must be forced into a surface correspondence relationship, and segments which are in correspondence must be forced to agree. Correspondence relationships between segments are implemented via the family of CoRR constraints, which may be given proximity restrictions to specify the distance at which they operate; in this analysis, I will not explicitly note the domain of these constraints in the discussion, since we restrict ourselves exclusively to adjacent pairs of segments. Segments which correspond are penalised for disagreement in a given feature $[\mathrm{F}]$ by IDENT constraints: to resolve this, the segments are assimilated. (Alternately, in dissimilatory processes, segments become less similar in order to avoid being correspondents; this operation is beyond the scope of this discussion.)

(12) Corr-A↔B: Assign a violation to a pair of adjacent segments not in correspondence in the output. For a string $S$ and adjacent segments $a \in S$ and $b \in S$, a relation must be established between $a$ and $b$. IDENT-CC[F]: Assign a violation to corresponding segments disagreeing in [F] specification.

CORR constraints occupy a fixed hierarchy scaled by similarity: correspondence between more similar segments outranks correspondence between less similar segments. An example, adapted from Rose and Walker 2004, is given in (13) below:

Highest similarity
CORR-N↔N
CoRR-D $\leftrightarrow \mathrm{D}$
identical

Less similarity
CorR-N↔D
agree in [voice]
disagree in [nasal]

\author{
Lowest similarity \\ CORR-N↔T \\ disagree in [voice] \\ disagree in [nasal]
}

CoRR constraints are here defined symmetrically (as I indicate by the bidirectional arrow $\leftrightarrow$ ): if A is a correspondent of B, then B is a correspondent of A. I note that in the formulation given in this section, the linear order in which segments subject to correspondence appear in the string is irrelevant; a sequence $a b$ and a sequence $b a$ are not distinguished by a CORR-A $\leftrightarrow \mathrm{B}$ constraint, which requires only that the constituents of such sequences enter the formal correspondence relationship. I will later show that this is in turn an unsatisfying, but easily-repaired, account of the typological problem, and will revisit these remarks in greater detail in section 5 .

4.2 Implementation The appeal of Agreement by Correspondence in predicting the behavior of nasallateral and lateral-nasal sequences is the intuition which it captures about the typological properties of the sequences targeted: assimilation in homorganic sequences (more similar) is generally preferred to assimilation in heterorganic sequences (less similar), and assimilation between nasals and laterals is preferred to assimilation between stops and laterals. Consider the similarity hierarchy given in (13); this can then be adapted to generate the correspondence constraint types required to capture certain implicational generalizations.

(14) Highest similarity CORR-N↔N CORR-L↔L identical
Less similarity CORR-N↔L

agree in place, sonorancy disagree in laterality

\section{Lowest similarity CORR-M↔L}

agree in sonorancy disagree in place, laterality 
(15)

Highest similarity
CORR-N↔N
CoRR $-\mathrm{L} \leftrightarrow \mathrm{L}$
identical

\author{
Less similarity \\ CORR-N↔L \\ agree in place, sonorancy \\ disagree in laterality
}

\author{
Lowest similarity \\ CORR-T↔L \\ agree in place \\ disagree in sonorancy, laterality
}

The scales given in (14) and (15) return part of the hierarchy of susceptibility to assimilation presented in (5) above: the higher-ranking the ConR for a pair of segments is, the more susceptible we predict those segments will be to assimilations driven by IDENT-XX[F]. This then readily generates several favorable predictions. First, in this analysis stop-lateral clusters TL are predicted to be less susceptible to assimilatory repair, due to reduced phonological similarity: CORR-N↔L $\gg$ CORR-T $\leftrightarrow$ L. Second, heterorganic nasal-lateral clusters ML must be less susceptible to assimilation than homorganic $\mathrm{NL}$, for an identical reason: CoRR-N↔L $\gg$ CORR-M↔L.

This proposal, however, does not (yet) predict all attested languages. Recall the Koasati example in (4):

(16) Koasati (Muskogean; Kimball 1991)

$\begin{array}{lll}\text { /i:t-il-noca/ } & \text { [i:tinnoca] } & \text { 'bedroom' } \\ \text { /am-layki/ } & \text { [allayki] } & \text { 'my dung' } \\ \text { /mal-mahka/ } & \text { [malmahka] } & \text { 'lightning' }\end{array}$

It's straightforward to demonstrate that [i:tinnoca] and [allayki] are predicted by our analysis, but that [malmahka] is not, as below in (17), (18), (19).

(17)

\begin{tabular}{|c|c|c|c|c|}
\hline & /i:t-il-noca/ & IDENT-CC[LAT & CORR-N↔L & IDENT-IO[LAT] \\
\hline \hline $\begin{array}{c}\text { correspond } \\
\text { agree } \text { in laterality }\end{array}$ & i:tin $\mathrm{n}_{x} \mathrm{oca}$ & & & $*$ \\
\hline $\begin{array}{c}\text { correspond } \\
\text { disagree in laterality }\end{array}$ & $\mathrm{i}: \mathrm{ti} \mathrm{l}_{x} \mathrm{n}_{x} \mathrm{oca}$ & $* !$ & & \\
\hline $\begin{array}{c}\text { don't correspond } \\
\text { agree in laterality }\end{array}$ & $\mathrm{i}: \mathrm{tin}_{x} \mathrm{n}_{y} \mathrm{oca}$ & & $* !$ & \\
\hline $\begin{array}{c}\text { don't correspond } \\
\text { disagree in laterality }\end{array}$ & $\mathrm{i}: \mathrm{til}_{x} \mathrm{n}_{y} \mathrm{oca}$ & & $* !$ & \\
\hline
\end{tabular}

(18)

\begin{tabular}{|c|c|c|c|c|}
\hline & /am-layki/ & IDENT-CC[LAT] & CORR-N $\leftrightarrow \mathrm{L}$ & IDENT-IO[LAT] \\
\hline \hline $\begin{array}{c}\text { correspond } \\
\text { agree } \text { in laterality }\end{array}$ & $\mathrm{al}_{x} 1_{x}$ ayki & & & $*$ \\
\hline $\begin{array}{c}\text { correspond } \\
\text { disagree in laterality }\end{array}$ & $\mathrm{am}_{x} 1_{x}$ ayki & $* !$ & & \\
\hline $\begin{array}{c}\text { don't correspond } \\
\text { agree in laterality }\end{array}$ & $\mathrm{al}_{x} 1_{y}$ ayki & & $* !$ & \\
\hline $\begin{array}{c}\text { don't correspond } \\
\text { disagree in laterality }\end{array}$ & $\mathrm{am}_{x} 1_{y}$ ayki & & $* !$ & \\
\hline
\end{tabular}

(19)

\begin{tabular}{|c|c|c|c|c|}
\hline & $/ \mathrm{mal}^{-\mathrm{mahka} /}$ & IDENT-CC[LAT] & CORR-N $\leftrightarrow \mathrm{L}$ & IDENT-IO[LAT] \\
\hline \hline $\begin{array}{c}\text { correspond } \\
\text { agree in laterality }\end{array}$ & ¿mam $\mathrm{m}_{x}$ ahka & & & $*$ \\
\hline $\begin{array}{c}\text { correspond } \\
\text { disagree in laterality }\end{array}$ & $\mathrm{mal}_{x} \mathrm{~m}_{x}$ ahka & $* !$ & & \\
\hline $\begin{array}{c}\text { don't correspond } \\
\text { agree in laterality }\end{array}$ & $\operatorname{mam}_{x} \mathrm{~m}_{y}$ ahka & & $* !$ & \\
\hline $\begin{array}{c}\text { don't correspond } \\
\text { disagree in laterality }\end{array}$ & $-\mathrm{mal}_{x} \mathrm{~m}_{y}$ ahka & & $* !$ & \\
\hline
\end{tabular}

Why does this incorrect prediction arise? As defined, the correspondence relation governing our analysis encodes no distinction between LM and ML; in the next section, I offer a solution. 


\section{Asymmetry}

In this section, I propose a modification to the formalism above that repairs the remaining descriptive inadequacies. We have noted above that NL-repairing systems in which LN assimilations never arise are attested and quite frequent; such systems are problematic for the current state of the analysis, as is the apparent nonexistence of the inverse case. Consider a CoRR-A $\leftrightarrow \mathrm{B}$ correspondence constraint, as defined in [§4.1]: this definition makes reference solely to the adjacency of the segments $a$ and $b$ in the string and not to their order, and thus necessarily cannot distinguish between a sequence $a b$ and a sequence $b a$. A successful analysis needs to adequately and restrictively generate the typological generalizations we derive above; if we are not able to ban systems that assimilate LN but not NL we may overpredict, and we must be able to predict the attested systems in which NL assimilates without LN doing so.

I'll now examine the behavior of a non-symmetric surface correspondence relation. This is not a novel proposal, although its utility and economy have previously been called into question: earlier work in $\mathrm{ABC}$ (Walker 2000, 2001; Hansson 2001, 2010) has treated correspondence as asymmetric in order to handle cases in which assimilation has a particular known directionality, i.e. occurs in a strictly progressive or strictly regressive manner. However, as Bennett (2013) observes, the direction of harmony does not follow from the direction of correspondence, as we can demonstrate simply; contra Bennett, however, I argue that this does not imply that asymmetric correspondence lacks predictive advantages. Consider a hypothetical system in which we want to generate strictly right-to-left voicing assimilation: /td/ surfaces as [dd]. We may suggest a constraint CORR-T $\leftarrow$ D, outlined in (20) after Walker 2001, Bennett 2013:

(20) Corr-T $\leftarrow \mathrm{D}: \quad$ Assign a violation to a $[\mathrm{t}]$ which is not in correspondence with a following [d]. For a string $S$ and adjacent segments $t \in S$ and $d \in S$, a relation must be established from $d$ to $t$.

CoRR-T $\leftarrow \mathrm{D}$ requires correspondence strictly from right to left: a [d] in the string forces a preceding [t] to correspond with itself, but cannot affect a following [t]. It's straightforward to demonstrate, however, that right-to-left correspondence does not imply right-to-left harmony, and that CORR-T $\leftarrow \mathrm{D}$ may be satisfied by both [tt] and [dd]; I illustrate the problem in (21).

(21) The operation of a strictly right-to-left correspondence relation

\begin{tabular}{|c|c|c|c|c|}
\hline & $/ \mathrm{td} /$ & IDENT-CC[VOI] & CORR-T $\leftarrow \mathrm{D}$ & IDENT-IO[VOI] \\
\hline \hline correspond, agree in voice & $\mathrm{t}_{x} \mathrm{t}_{x}$ & & & $*$ \\
\hline correspond, agree in voice & $\mathrm{d}_{x} \mathrm{~d}_{x}$ & & & $*$ \\
\hline correspond, disagree in voice & $\mathrm{t}_{x} \mathrm{~d}_{x}$ & $* !$ & & \\
\hline don't correspond, disagree in voice & $\mathrm{t}_{x} \mathrm{~d}_{y}$ & & $* !$ & \\
\hline
\end{tabular}

\begin{tabular}{|c|c|c|c|c|}
\hline & $/ \mathrm{dt} /$ & IDENT-CC[VOI] & CORR-T $\leftarrow \mathrm{D}$ & IDENT-IO[VOI] \\
\hline \hline correspond, agree in voice & $\mathrm{t}_{x} \mathrm{t}_{x}$ & & & $* !$ \\
\hline correspond, agree in voice & $\mathrm{d}_{x} \mathrm{~d}_{x}$ & & & $* !$ \\
\hline correspond, disagree in voice & $\mathrm{t}_{x} \mathrm{~d}_{x}$ & $* !$ & & \\
\hline don't correspond, disagree in voice & $\mathrm{t}_{x} \mathrm{~d}_{y}$ & & & \\
\hline
\end{tabular}

For the input sequence /td/, Corr-T $\leftarrow \mathrm{D}$ does not discriminate between output candidates [tt] and [dd], being satisfied by either configuration (as long as correspondence remains intact; for correspondence to operate, voicing must agree across the sequence to satisfy IDENT-CC[VoI], but this is true of both candidates), and thus is unable to predict directionality patterns in assimilation. Considering, however, an input /dt/, we observe that CORR-T $\leftarrow \mathrm{D}$ will never be invoked, and that therefore we predict no assimilation to be driven by this particular constraint in a sequence of this type. We then have a correspondence constraint that discriminates between TD and DT sequences, unlike the problematic analysis in §4]: this is not useful if our goal is to model directionality, but since our goal is to model the asymmetry in targeting between NL and LN, the significance is immediately clear. I outline below an analysis of systems in which NL sequences assimilate, but LN sequences do not, with reference to the data in (23).

(23) Meitei(lon) (Tibeto-Burman; Chelliah 1997, and own field data)

$$
\text { /pu-sin-loga/ [pusillagə] 'after bringing in' NL assimilates }
$$



/təm-li/
[təmmi]
'is learning'
ML assimilates
/loikol-ni/
[ləikolni]
'garden.cop'
LN does not

In Meiteilon, both homorganic and heterorganic nasal-lateral (NL, ML) sequences assimilate, but homorganic NL does not. The straightforward analysis predicated on similarity is then problematic: we expect similarity to be higher in LN than ML, promoting assimilation. I suggest that we can solve the descriptive problem by separating out the fixed scale of correspondence constraints given in (14) into two separate scales corresponding to the two possible directions of correspondence: that is, CoRR-N $\leftarrow \mathrm{L} \gg$ CORR-M $\leftarrow \mathrm{L}(/ \mathrm{nl} /$ sequences are more susceptible to assimilation than $/ \mathrm{ml} /, / \mathrm{nl} /$, or $/ \mathrm{yl} /$ sequences $)$, and independently, CORR-L $\leftarrow \mathrm{N} \gg$ CORR-L $\leftarrow \mathrm{M}(/ \mathrm{ln} /$ sequences are more susceptible to assimilation than $/ \mathrm{lm} /$, $/ \mathrm{ln} /$, or $/ \mathrm{ln} /$ sequences). If we admit this decomposition of the correspondence relation, both scales seem

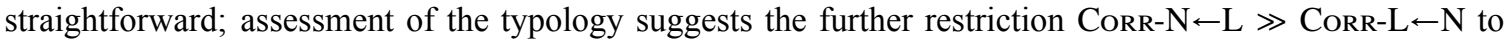
restrict pathological overgeneration (LN assimilation strictly implies NL assimilation in the sample), although we must then discuss the groundedness of this proposal. In 24 and 25, we see that ranking IDENT-IO[LAT] $\gg$ CORR-L $\leftarrow \mathrm{N}$ causes highly-ranked faith to the input to be violated for any candidate with assimilation in an NL sequence. This generates the descriptive facts satisfactorily: we're able to predict systems that only repair NL sequences, or that repair only NL and ML.

(24) Assimilation in NL sequences in Meiteilon.

\begin{tabular}{|c|c|c|c|c|c|}
\hline & /pu-sin-laga/ & IDENT-CC[LAT] & CORR-N־L & IDENT-IO[LAT] & CORR-L $\leftarrow N$ \\
\hline $\begin{array}{c}\text { correspond } \\
\text { agree in laterality }\end{array}$ & 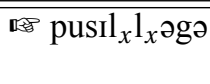 & & & * & \\
\hline $\begin{array}{l}\text { correspond } \\
\text { don't agree }\end{array}$ & $\operatorname{pusin}_{x} 1_{x}$ əgə & $* !$ & & & \\
\hline $\begin{array}{c}\text { don't correspond } \\
\text { agree }\end{array}$ & $\operatorname{pusil}_{x} 1_{y}$ əgə & & $* !$ & * & \\
\hline $\begin{array}{c}\text { don't correspond } \\
\text { don't agree }\end{array}$ & $\operatorname{pusin}_{x} 1_{y}$ əgə & & *! & & \\
\hline
\end{tabular}

(25) Non-assimilation in LN sequences in Meiteilon.

\begin{tabular}{|c|c|c|c|c|c|}
\hline & /ləikol-ni/ & IDENT-CC[LAT] & CORR-N $\leftarrow \mathrm{L}$ & IDENT-IO[LAT] & CORR-L $\leftarrow \mathrm{N}$ \\
\hline $\begin{array}{c}\text { correspond } \\
\text { agree in laterality }\end{array}$ & $\operatorname{loikol}_{x} 1_{x} \mathrm{i}$ & & & $* !$ & \\
\hline $\begin{array}{l}\text { correspond } \\
\text { don't agree }\end{array}$ & $\operatorname{loikol}_{x} \mathrm{n}_{x} \mathrm{i}$ & $* !$ & & & \\
\hline $\begin{array}{c}\text { don't correspond } \\
\text { agree }\end{array}$ & ləikol $_{x} 1_{y} \mathrm{i}$ & & & $* !$ & \\
\hline $\begin{array}{c}\text { don't correspond } \\
\text { don't agree }\end{array}$ & ləikol ${ }_{x} n_{y} \mathrm{i}$ & & & & * \\
\hline
\end{tabular}

There is a broader theoretical point of some interest here. Asymmetric correspondence relations don't handle directionality, but what they do handle is those cases in which the presence or absence of assimilation is dependent on the order of segments in the string. We're not attempting to model directionality patterns, but we are interested in modelling asymmetries in target selection.

\section{Conclusions}

I have presented an analysis of assimilations in sequences of nasals and laterals that attributes such patterns to a dispreference for phonologically similar but non-identical segments within a small domain. Centrally, I have suggested that asymmetry in correspondence relations, rather than being a failed attempt to handle directionality within correspondence theory, provides a way to build into the analysis cases in which sequences of identical segments exhibit different behavior dependent on the ordering of those segments within the string. It remains to be understood how formally parallel long-distance and local patterns in nasalization and lateralization must be, and it is not yet clear whether long-distance lateral-rhotic and nasal-rhotic effects display typological asymmetries that would admit a similar analysis - future extensions of this work will address these issues. 


\section{References}

Abdel-Massih, Ernest T. 1971. A Reference Grammar Of Tamazight. Ann Arbor: Center for Near Eastern and North African Studies, University of Michigan.

Anderson, Gregory D. S. 1998. Xakas. München: Lincom Europa.

Baertsch, Karen. 2002. "An Optimality Theoretic Approach To Syllable Structure: The Split Margin Hierarchy.". Ph.D, Indiana University.

Baertsch, Karen and Stuart Davis. 2000. "Turkic C+/1/ cluster phonology." Paper presented at MCWOP.

Bennett, William G. 2013. "Dissimilation, Consonant Harmony, And Surface Correspondence.". Ph.D, Rutgers, The State University of New Jersey.

Bläsing, Uwe. 2003. "Kalmuck.” In The Mongolic Languages, 229-247. London: Routledge.

Blevins, Juliette. 1994. "A Place For Lateral In The Feature Geometry*”. J. Ling. 30 (02): 301. doi:10.1017/s0022226700016686.

Chelliah, Shobhana Lakshmi. 1997. A Grammar Of Meithei. Berlin: Mouton de Gruyter.

Clark, Larry V. 1998. Turkmen Reference Grammar. Wiesbaden: Harrassowitz.

Comrie, Bernard. 1997. "Tatar Phonology". In Phonologies Of Asia And Africa 2, edited by Alan S. Kaye, 899-911. Winona Lake: Eisenbrauns.

Davis, Stuart and Seung-Hoon Shin. 1999. "The syllable contact constraint in Korean: An OptimalityTheoretic analysis." Journal of East Asian Linguistics 8, 285-312.

Dissassa, Melaku. 1980. "Some aspects of Oromo phonology." Ph.D, Kansas State University.

Gouskova, Maria. 2004. "Relational Hierarchies In Optimality Theory: The Case Of Syllable Contact". Phonology 21 (2): 201-250. doi:10.1017/s095267570400020x.

Hahn, Reinhard F, and Ablahat Ibrahim. 1991. Spoken Uyghur. Seattle: University of Washington Press.

Hansson, Gunnar Ólafur. 2001. "Theoretical and Typological Issues in Consonant Harmony". Ph.D, University of California, Berkeley.

Hansson, Gunnar Ólafur. 2010. Consonant Harmony: Long-Distance Interaction in Phonology. University of California Publications in Linguistics, 145. Berkeley, CA: University of California Press.

Harrell, Richard S. 1962. A Short Reference Grammar of Moroccan Arabic. Washington: Georgetown University Press.

Harrison, K. David. 2000. "Topics in the Phonology and Morphology of Tuvan". PhD dissertation, Yale University.

Inkelas, Sharon and Stephanie Shih. 2013. "Unstable surface correspondence as the source of local conspiracies." Paper presented at NELS 44, University of Connecticut, Oct. 18-20, 2013.

Iverson, G. and Hyang-Sook, Sohn. 1994. "Liquid representation in Korean." In Theoretical Issues in Korean Linguistics, edited by Young-Key Kim-Renaud, 77-100. Chicago: University of Chicago Press.

Jakobi, Angelika. 1990. A Fur grammar. Hamburg: Helmut Buske Verlag.

Kavitskaya, Darya. 2010. Crimean Tatar. München: Lincom Europa.

Khan, Geoffrey. 2008. The Neo-Aramaic Dialect of Barwar. Leiden: Brill.

Kibrik, Alexander, Sandro Kodzasov and Irina Muravyova. 2000. Язык и фольклор алюториев [The Language and Folklore of the Alutors]. Moscow: Imli Ran.

Kimball, Geoffrey. 1991. Koasati Grammar. Lincoln, Nebraska: University of Nebraska Press.

Lionnet, Florian. 2014. "Doubly Triggered Harmony in Laal as Subphonemic Agreement by Correspondence". Proceedings Of The Annual Meetings On Phonology 1 (1). doi:10.3765/amp.v1i1.38.

Odden, David Arnold. 2005. Introducing Phonology. Cambridge, UK: Cambridge University Press.

Macknight, Charles Campbell. 2012. Bugis and Makassar : two short grammars. Canberra: Karuda Press.

Maslova, Elena. 2003. Tundra Yukaghir. München: Lincom Europa.

Ongaye, Oda Orkaydo. 2013. A grammar of Konso. PhD dissertation, Leiden University.

Özkan, Nevzat. 1996. Gagavuz Türkçesi Grameri. Türk Dil Kurumu Yayinlari 657. Ankara: Ankara University.

Pons-Moll, Claudia. 2013. "It is all downhill from here: the role of Syllable Contact in Romance languages." Probus 23 (1). doi:10.1515/prbs.2011.004.

Quick, Philip A. 2003. A Grammar Of The Pendau Language. Canberra, A.C.T.: Pacific Linguistics, Research School of Pacific and Asian Studies, Australian National University.

Rhodes, Russell. 2012. "Vowel Harmony as Agreement by Correspondence". Annual Report of the UC 
Berkeley Phonology Lab (2012), pp.138-168.

Roos, Marti. 2000. "The Western Yugur (Yellow Uygur) Language: Grammar, Texts, Vocabulary”. Ph.D, Leiden University.

Rose, Sharon, and Rachel Walker. 2004. "A Typology Of Consonant Agreement As Correspondence". Language 80 (3): 475-531. doi:10.1353/lan.2004.0144.

Sadock, Jerrold M. 2003. A Grammar of Kalaallisut (West Greenlandic Inuktitut). München: Lincom Europa. Schuh, Russell G. 1998. A Grammar Of Miya. Berkeley: Univ. of California Press.

Schulze, Wolfgang. 1997. Tsakhur. München: Lincom Europa.

Seegmiller, Steve. 1996. Karachay. München: Lincom Europa.

Seo, Misun. 2003. "A Segment Contact Account Of The Patterning Of Sonorants In Consonant Clusters". $\mathrm{Ph} . \mathrm{D}$, The Ohio State University.

van der Tuuk, H. N. 1971. A Grammar of Toba Batak. The Hague: Martinus Hijhoff.

van Engelenhoven, Aone. 2004. Leti, a language of Southwest Maluku. Leiden: KITLV Press.

van Putten, Marijn. 2013. "A Grammar of Awjila Berber (Libya) Based on Umberto Paradisi's Material." Ph.D, Leiden University.

Walker, Neil Alexander. 2013. "A Grammar of Southern Pomo: An Indigenous Language of California." Ph.D, University of California at Santa Barbara

Walker, Rachel. 2000. Nasalization, Neutral Segments and Opacity Effects. Garland, New York.

Walker, Rachel. 2009. "Similarity-sensitive blocking and transparency in Menominee". Paper presented at the 83rd Annual Meeting of the Linguistic Society of America. San Francisco, California. 9 January 2009.

Yip, Moira. 2005. "Variability in feature affiliations through violable constraints: The case of [lateral]."

In The Internal Organization of Phonological Segments, edited by Marc van Oostendorp and Jeroen van de Weijer, 63-92. Berlin: Mouton de Gruyter.

Youssef, Islam. 2013. "Place Assimilation in Arabic." Ph.D, University of Tromsø. 